\title{
BMJ Open Personality factors predict sleep-related shift work tolerance in different shifts at 2-year follow-up: a prospective study
}

\author{
Sunniva Straume Storemark, ${ }^{1}$ Ingrid Nesdal Fossum, ${ }^{1}$ Bjørn Bjorvatn, ${ }^{2,3}$ \\ Bente Elisabeth Moen, ${ }^{2}$ Elisabeth Flo, ${ }^{2}$ Ståle Pallesen ${ }^{1,3}$
}

To cite: Storemark SS, Fossum IN, Bjorvatn B, et al. Personality factors predict sleep-related shift work tolerance in different shifts at 2-year follow-up: a prospective study. BMJ Open 2013;3:e003696.

doi:10.1136/bmjopen-2013003696

- Prepublication history for this paper is available online. To view these files please visit the journal online (http://dx.doi.org/10.1136/ bmjopen-2013-003696).

Received 31 July 2013 Revised 25 September 2013 Accepted 9 October 2013

CrossMark

For numbered affiliations see end of article.

Correspondence to Sunniva Straume Storemark; sst110@student.uib.no

\section{ABSTRACT}

Objectives: The aim of the present study was to investigate whether the personality variables morningness, flexibility, languidity and hardiness could predict sleep-related shift work tolerance for the day, evening and night shifts, respectively.

Design: Prospective study design with questionnaires administered in winter 2008/2009 (wave 1) and 2 years later in spring 2011 (wave 3).

Setting: Different healthcare institutions in Norway. Participants: The sample comprised in all 700 nurses working a three-shift rotating schedule.

Primary and secondary outcome measures: The personality variables were assessed at wave 1 , as were the demographic, lifestyle and work-related variables. Sleep-related shift work tolerance, assessed at wave 3 , was measured separately for the day, evening and night shifts with the Bergen Shift Work Sleep Questionnaire. Results: Morningness was positively associated with sleep-related day shift tolerance $(p<0.001)$. Flexibility was positively associated with sleep-related tolerance for the evening as well as night shift $(p<0.001)$. Furthermore, languidity was negatively associated with sleep-related shift tolerance for the day, evening and night shifts $(p<0.001,<0.01,<0.05$, respectively). Hardiness was positively associated with sleep-related tolerance for the day, evening and night shifts $(p<0.001,<0.01,<0.05$, respectively). Age was negatively associated with sleeprelated shift tolerance for the day, night $(p<0.01)$ and evening shifts $(p<0.001)$.

Conclusions: The findings indicate that hardiness and languidity predict sleep-related shift work tolerance across all shift types among shift working nurses. The effects of flexibility and morningness seem to depend on the shift schedule. By and large, our results are in accordance with previous studies; however, we have now demonstrated the prospective importance of personality in relation to sleep-related shift work tolerance across different shifts.

Shift work can be defined as work that occurs between 19:00 and 6:00 ${ }^{1}$ and often refers to an arrangement of alternating day

\section{Strengths and limitations of this study}

- This study was based on a prospective study design.

- It is the first study to investigate whether personality variables predict sleep-related shift work tolerance separately for different shifts.

- The gender distribution was skewed with a female preponderance.

shifts, evening shifts and/or night shifts. In night shifts, the majority of the working hours take place between 22:00 and 6:00. ${ }^{2}$ In 2012, $33.2 \%$ of the workers in Norway reported working outside ordinary work hours, that is, outside Monday to Friday from 6:00 to $18: 00 .^{3}$ The same survey also showed that $15 \%$ reported working night shifts occasionally or regularly. ${ }^{3}$

Several studies have consistently shown that shift work is associated with a range of negative health consequences, for example, cardiovascular disease, ${ }^{4}$ gastrointestinal symptoms along with peptic ulcer disease, ${ }^{5}$ breast cancer among women, ${ }^{6}$ metabolic disturbances ${ }^{7}$ and poor mental health. ${ }^{8}$ Working shifts may also disturb family life and impair social relationships. ${ }^{9}$

Sleep problems are the most common health symptom among shift workers, ${ }^{2}$ with difficulties falling asleep, not getting enough sleep and wake time sleepiness being especially pronounced. ${ }^{10}$ Reduced sleep duration will normally result in reduced performance, as well as higher error rate and fatigue. ${ }^{10} \mathrm{In}$ line with this, shift work has been linked to reduced productivity ${ }^{11}$ and increased accident risk, especially during the night shift. ${ }^{12}$

Night work involves sleeping and performing activities at times when the body is not biologically adapted to these behaviours. ${ }^{13}$ The circadian rhythm strongly affects human performance, which is poorer during nighttime compared to daytime. ${ }^{14}$ One major 
reason for the health problems in shift work relates to the conflict between displaced work hours and the output from the biological clock. ${ }^{10}$

Still, not everyone finds it difficult to adapt to this kind of work arrangement. The ability to work shifts without experiencing negative consequences is referred to as 'shift work tolerance'. ${ }^{15}$ High shift work tolerance has been defined as the absence of digestive troubles, persisting fatigue, unusual nervousness and sleep alterations when working shifts. ${ }^{15}$ Several factors such as individual characteristics, lifestyle factors, work schedule, working conditions, family and social conditions and health are likely to affect shift work tolerance. ${ }^{16}$

Among the most commonly studied individual characteristics in relation to shift work tolerance, one finds morningness, flexibility, languidity and hardiness, in addition to age and gender. ${ }^{17}$ Morningness-eveningness refers to a dimension often described as a trait that reflects individuals' diurnal preferences. ${ }^{18}$ Individuals with high scores on morningness have their peak of alertness earlier in the day relative to individuals with low scores. Meanwhile, flexibility denotes the ability to sleep and work at odd times of the day, whereas languidity reflects difficulties overcoming drowsiness and lethargy following a reduction in sleep. ${ }^{19}$ Hardiness is regarded as a general resilience factor concerning coping with stress and illness. ${ }^{20}$ In a recent review, we noted that low scores on morningness, high scores on flexibility and low scores on languidity were associated with better shift work tolerance in the majority of the included studies. ${ }^{17}$ In the same review, we concluded that young age and male gender were also associated with a higher shift work tolerance. However, the review also calls attention to the inconsistent results across studies and emphasises the need for more prospective studies regarding personality variables and their relation to shift work tolerance.

One explanation for inconsistent findings may be that shift work tolerance so far has not been assessed in relation to specific shifts. For example, it may be assumed that individuals with high scores on morningness (morning larks) cope well with day shifts but cope poorly with night shifts, whereas the opposite is assumed to be the case for individuals with low scores on morningness (night owls). An obstacle for investigating tolerance to different shifts has been the lack of adequate instruments assessing shift-specific tolerance. However, recently, the Bergen Shift Work Sleep Questionnaire (BSWSQ) was constructed for the purpose of assessing symptoms of shift-related sleep-wake disturbances separately for the day, evening and night shifts, as well as rest days. ${ }^{21}$ Against this backdrop, we conducted a study, based on the BSWSQ, that investigated whether personality, demographic, lifestyle and work-related variables were associated with sleep-related shift work tolerance relevant to specific work shifts.

On the basis of the reviewed literature, the following hypotheses were investigated
Hypothesis 1: Morningness is positively associated with sleep-related day shift tolerance, while it is negatively associated with sleep-related shift work tolerance for the evening and night shifts.

Hypothesis 2: Languidity is negatively associated with sleep-related shift work tolerance for all three shift types.

Hypothesis 3: Flexibility is positively associated with sleep-related shift work tolerance for all three shift types.

Hypothesis 4: Hardiness is positively associated with sleep-related shift work tolerance for all three shift types.

\section{METHODS}

\section{Sample and procedure}

The data used in the present study were obtained from the longitudinal questionnaire study entitled 'the SUrvey of Shift work, Sleep and Health' (SUSSH). A sample $(\mathrm{N}=6000)$ was initially drawn from a population consisting of registered members of the Norwegian Nurses Organisation (NNO), which includes most of the nurses currently working in Norway. The sample was stratified by the time passed since graduating as a nurse and was divided into five strata, each containing 1200 nurses maintaining at least a $50 \%$ work position. The five different strata in this case were $0-11$ months, $1-3$ years, 3.1-6 years, 6.1-9 years and $9.1-12$ years. The nurses received questionnaires by postal mail during the winter 2008/2009 (wave 1), with a prepaid return envelope. Two reminders were sent to non-responders. A total of 600 letters were returned due to wrong addresses, and thus the survey sample consisted of 5400 nurses. A total of 2048 nurses completed and returned the questionnaire, thereby yielding a response rate of $38 \%$. Wave 3 was conducted 2 years later, and 1533 participants from wave 1 responded, yielding a response rate of $74.9 \%$. Among the responders, 700 $(45.7 \%)$ reported having a 'three-shift rotation schedule' (day, evening and night shifts) in wave 3. These were included in our analyses, since their responses allowed for an estimation and comparison of the predictive effect of personality on shift tolerance for all shifts.

\section{Instruments}

The instruments relevant for this study and used for assessment at wave 1 comprised four instruments measuring personality in terms of morningness, hardiness, flexibility and languidity. Demographic, lifestyle and work-related variables were also assessed at wave 1 . This procedure was undertaken in order to investigate whether personality variables could predict sleep problems associated with different shifts at wave 3 when controlling for relevant demographic, health and work-related variables at wave 1 .

Demographics and health-related variables: The questions concerning the respondents' background included age, 
gender, marital status, children living at home, smoking and caffeine consumption at wave 1 .

Work-related variables: The questionnaire also included questions about the percentage of full-time equivalent, number of years worked as a nurse and number of night shifts worked during the previous year.

The Alcohol Use Disorders Identification Test-Consumption (AUDIT-C): Questions concerning alcohol consumption were used to identify the participants' drinking habits. The AUDIT-C scale is a valid primary care screening test for heavy drinking and/or active alcohol abuse or dependence. ${ }^{22}$ The scale comprises three items addressing the frequency and quantity of drinking, where higher scores indicate higher alcohol consumption. In this cohort, AUDIT-C was assessed at wave 3 with Cronbach's $\alpha$ of 0.51 .

The Diurnal Scale (DS): DS consists of seven items assessing the morningness-eveningness dimension. Each item is rated on a four-point scale where the respondents indicate their preferred time for conducting certain activities. Higher scores on the seven items indicate higher levels of morningness. ${ }^{23}$ Cronbach's $\alpha$ for DS in the present study was 0.63 . DS has previously been shown to have good reliability and validity. ${ }^{24}$

The Revised Dispositional Resilience (Hardiness) Scale: The Hardiness Scale consists of 15 statements representing different attitudes and thoughts. Respondents rate the statements on a 4-point scale, ranging from 'not at all true' to 'completely true'. The scale has three subdimensions, consisting of commitment, control and challenge. ${ }^{25}$ The hardiness scale has been translated into Norwegian, ${ }^{26}$ and in the present study, the revised Norwegian version was used. In the present study, Cronbach's $\alpha$ for the Revised Hardiness Scale was 0.73.

The revised Circadian Type Inventory (rCTI): The instrument consists of 11 questions concerning daily sleep, wake and activity habits and preferences and comprises a flexibility subscale (6 items) and a languidity subscale (5 items) ${ }^{19}$ Flexibility refers to the ability to sleep and work at odd times, whereas languidity is related to difficulties overcoming drowsiness and feelings of lethargy following a reduction in sleep. The respondents give their answers on a five-point scale ranging from 1 ('almost never') to 5 ('almost always'). High scores indicate a tendency towards possessing the trait to a high degree. Cronbach's $\alpha$ for the flexibility and languidity subscales in the present study were 0.79 and 0.66 , respectively. rCTI has been shown to possess high reliability and validity. ${ }^{19}$

The Bergen Shift Work Sleep Questionnaire (BSWSQ): BSWSQ systematically assesses the insomnia symptoms and sleepiness/tiredness separately for different work shifts (day, evening, night shifts) and rest days. ${ }^{21}$ The questionnaire comprises the following six symptom questions: difficulties falling asleep, difficulties maintaining sleep, early morning awakening, non-restorative sleep and sleepiness/tiredness during work hours and during time off work on workdays. Each item is rated on a fivepoint scale, ranging from 0 to 4 ('never', 'rarely', 'sometimes', 'often' and 'always'). A composite score for each shift is calculated, ranging from 0 to 24 . An increasing sum score indicates increased sleep-wake disturbance in relation to that shift. In order to facilitate the interpretation of the results, the scores were reversed so that higher scores reflect higher levels of sleep-related shift work tolerance. Cronbach's $\alpha$ for the day, evening and night shifts in the present study were $0.71,0.76$ and 0.79 , respectively. The scale has demonstrated good psychometric properties. $^{21}$

\section{Statistics}

Data were analysed using SPSS V.19.0 (SPSS Inc, 2010). Three separate hierarchical multiple regression analyses were conducted where the composite scores for day, evening and night shift tolerance, respectively assessed by BSWSQ comprised the dependent variables. In the first block, the demographic variables age, gender (male $=1$, female=2), marital status (married/partner $=1$, unmar$\mathrm{ried} /$ divorced/single/widow/widower/separated $=2$ ) and children living at home (yes=1, no=2) from wave 1were entered. In the second block, lifestyle variables concerning smoking (yes $=1, \mathrm{no}=2$ ), caffeine consumption (number of glasses/cups of caffeine beverages consumed each day) as well as the composite score on AUDIT-C derived from wave 1 were entered. In the third block, work-related variables in terms of the percentage of full-time equivalent, number of years worked as a nurse and number of night shifts reported at wave 1 were entered. In the fourth and final block, the personality variables morningness, languidity, flexibility and hardiness, all assessed at wave 1, were entered. Preliminary analyses were performed to ensure that the assumption of normality was not violated, as well as checking for multicollinearity, linearity and homoscedasticity.

\section{RESULTS}

Table 1 presents an overview of the study variables, their mean scores and SDs in the present sample. Nominal variables are presented in terms of their distribution. The number of respondents varied across the study variables due to missing data, ranging from 629 to 700 .

Table 2 shows the results of the hierarchical regression analysis with the score on BSWSQ for sleep-related day shift tolerance as the dependent variable. In the first block, the demographic variables from wave 1 were entered and explained $1.5 \%$ of the variance, $\mathrm{F}(4,580)$ $=2.20 \mathrm{p}>0.05$. In the second block, lifestyle variables from wave 1 explained a further $0.4 \%$ of the variance, $\mathrm{F}(7,577)$ $=1.55, \mathrm{p}>0.05$. In the third block, the work-related variables reported from wave 1 explained an additional $0.1 \%$ of the variance, $\mathrm{F}(10,574)=1.12, \mathrm{p}>0.05$. In the final block, the personality variables assessed at wave 1 were found to explain a total of $14.2 \%$ of the variance, $\mathrm{F}(14,570)=7.85$, $\mathrm{p}<0.001$. The model as a whole explained $16.2 \%$ of the variance. Results from the final block showed that age was significantly and negatively associated with sleep-related 
Table 1 Descriptive study variables

\begin{tabular}{|c|c|c|c|}
\hline & $\mathbf{N}$ & $\begin{array}{l}\text { Mean/ } \\
\text { percentage }\end{array}$ & SD \\
\hline Age & 700 & 34.5 & 7.8 \\
\hline \multicolumn{4}{|l|}{ Gender } \\
\hline Female & 638 & $91.5 \%$ & \\
\hline Male & 59 & $8.5 \%$ & \\
\hline \multicolumn{4}{|l|}{ Marital status } \\
\hline Married/partner & 510 & $73.9 \%$ & \\
\hline Not married/no partner & 180 & $26.1 \%$ & \\
\hline \multicolumn{4}{|l|}{ Children } \\
\hline Children living at home & 302 & $43.1 \%$ & \\
\hline No children living at home & 371 & $55.1 \%$ & \\
\hline Caffeine (cups/glass per day) & 698 & 2.9 & 2.4 \\
\hline \multicolumn{4}{|l|}{ Smoking daily } \\
\hline Yes & 50 & $7.5 \%$ & \\
\hline No & 615 & $92.5 \%$ & \\
\hline AUDIT-C & 686 & 2.9 & 2.4 \\
\hline \multicolumn{4}{|l|}{ Percentage position } \\
\hline$<50$ & 15 & $2.2 \%$ & \\
\hline $50-75$ & 194 & $27.8 \%$ & \\
\hline $76-90$ & 98 & $14.1 \%$ & \\
\hline$>90$ & 390 & $56.0 \%$ & \\
\hline Years of work as nurse & 694 & 5.0 & 4.1 \\
\hline $\begin{array}{l}\text { Number of nights worked last } \\
\text { year }\end{array}$ & 639 & 32.5 & 22.7 \\
\hline Morningness & 679 & 17.7 & 3.3 \\
\hline Languidity & 675 & 20.6 & 3.5 \\
\hline Flexibility & 682 & 12.4 & 3.8 \\
\hline Hardiness & 686 & 31.7 & 4.3 \\
\hline $\begin{array}{l}\text { Sleep-related day shift } \\
\text { tolerance }\end{array}$ & 639 & 26.4 & 3.4 \\
\hline $\begin{array}{l}\text { Sleep-related evening shift } \\
\text { tolerance }\end{array}$ & 638 & 25.8 & 3.9 \\
\hline $\begin{array}{l}\text { Sleep-related night shift } \\
\text { tolerance }\end{array}$ & 629 & 22.2 & 4.7 \\
\hline
\end{tabular}

day shift tolerance $(\beta=-0.13, \mathrm{p}<0.01)$. Morningness was positively associated with sleep-related day shift tolerance $(\beta=0.17, p<0.001)$. Languidity was negatively associated with sleep-related day shift tolerance $(\beta=-0.23, \mathrm{p}<0.001)$. Hardiness was positively associated with sleep-related day shift tolerance $(\beta=0.15, \mathrm{p}<0.001)$.

Table 3 shows the results of the hierarchical regression analysis with the score on BSWSQ for sleep-related evening shift tolerance as the dependent variable. In the first block, the demographic variables from wave 1 explained $3 \%$ of the variance, $\mathrm{F}(4,579)=4.46, \mathrm{p}<0.01$. In the second block, lifestyle variables from wave 1 explained a further $0.1 \%$ of the variance, $\mathrm{F}(7,576)=2.63$, $\mathrm{p}<0.05$. In the third block, work-related variables reported from wave 1 explained an additional $0.1 \%$ of the variance, $\mathrm{F}(10,573)$ $=1.92, \mathrm{p}<0.05$. In the final block, the personality variables, all assessed at wave 1, explained a further $9 \%$ of the variance, $\mathrm{F}(14,569)=5.65, \mathrm{p}<0.001$. The model as a whole explained $12.2 \%$ of the variance. Results from the final block showed that age $(\beta=-0.18, p<0.001)$ and languidity $(\beta=-0.13, \quad \mathrm{p}<0.01) \quad$ were negatively associated with sleep-related evening shift tolerance. Flexibility was positively associated with sleep-related evening shift tolerance $(\beta=0.20, p<0.001)$. Also, hardiness was positively associated with sleep-related evening shift tolerance $(\beta=0.12, \mathrm{p}<0.01)$.

Table 4 shows the results of the hierarchical regression analysis with the score on BSWSQ for sleep-related night shift tolerance as the dependent variable. In the first block, the demographic variables from wave 1 explained $2.4 \%$ of the variance, $\mathrm{F}(4,571)=3.48, \mathrm{p}<0.01$. In the second block, lifestyle variables from wave 1 explained a further $0.6 \%$ of the variance, $\mathrm{F}(7,568)=2.45, \mathrm{p}<0.05$. In the third block, work-related variables reported from wave 1 explained an additional $0.5 \%$ of the variance, $\mathrm{F}$ $(10,565)=1.99, \mathrm{p}<0.05$. In the final block, the personality variables assessed at wave 1 were found to explain a further $17.3 \%$ of the variance, $F(14,561)=10.47$, $\mathrm{p}<0.001$. The model as a whole explained $20.7 \%$ of the variance. In the fourth and final block, age was significantly and negatively associated with sleep-related night shift tolerance $(\beta=-0.14, p<0.01)$. Languidity $(\beta=-0.10$, $\mathrm{p}<0.05)$ was negatively associated with sleep-related night shift tolerance. Flexibility $(\beta=0.37, \mathrm{p}<0.001)$ and hardiness $(\beta=0.09, \quad \mathrm{p}<.05)$ were positively associated with sleep-related night shift tolerance.

\section{DISCUSSION}

The present study aimed to investigate whether the personality variables morningness, flexibility, languidity and hardiness over a 2-year time span could predict sleep-related shift tolerance associated with three different shifts when controlling for relevant demographic, lifestyle and work-related variables. Sleep-related shift work tolerance was assessed by BSWSQ. After controlling for the relevant variables, hierarchical regression analyses showed that the personality variables explained $16.2 \%$ of the variance in sleep-related dayshift tolerance, $12.2 \%$ of the variance in sleep-related evening shift tolerance and $20.7 \%$ of the variance in sleep-related night shift tolerance. Based on these results, it appears that personality variables explain a substantial proportion of the variance in sleep-related shift work tolerance at follow-up, this being especially evident concerning sleep-related night shift tolerance.

Morningness was found to be positively associated with sleep-related day shift tolerance, suggesting that night owls have more sleep problems related to day shift work than do morning larks. This supports the first part of our first hypothesis and is in line with some previous studies showing a significant and positive relationship between morningness and shift work tolerance. ${ }^{17} 27$ Owing to their advanced circadian rhythm, daytimeworking adults with high scores on morningness have shorter sleep onset latency and longer sleep duration on weekdays than people with lower scores on morningness, ${ }^{28}$ findings which are in line with our results. The second part of the first hypothesis was not supported as 
Table 2 Hierarchical regression analysis with sleep-related day shift tolerance total score as the dependent variable $(\mathrm{N}=584)$

\begin{tabular}{|c|c|c|c|c|c|c|}
\hline Predictor & B & SE B & $\boldsymbol{\beta}$ & $\mathbf{t}$ & & $\mathrm{R}^{2} / \Delta \mathrm{R}^{2}$ \\
\hline Step 1 & & & & & & $0.015 / 0.015$ \\
\hline Age & -0.02 & 0.019 & -0.06 & -1.26 & & \\
\hline Gender $($ male $=1$, female $=2)$ & -0.30 & 0.508 & -0.02 & -0.60 & & \\
\hline Marital status (partner $=1$, no partner $=2$ ) & -0.23 & 0.347 & -0.03 & -0.67 & & \\
\hline Children $($ yes $=1$, no=2) & -0.79 & 0.328 & -0.11 & -2.40 & * & \\
\hline Step 2 & & & & & & $0.018 / .004$ \\
\hline Age & -0.02 & 0.021 & -0.05 & -0.98 & & \\
\hline Gender $($ male $=1$, female $=2)$ & -0.44 & 0.519 & -0.04 & -0.84 & & \\
\hline Marital status (partner $=1$, no partner $=2$ ) & -0.18 & 0.350 & -0.02 & -0.50 & & \\
\hline Children $($ yes $=1, \mathrm{no}=2)$ & -0.70 & 0.338 & -0.10 & -2.05 & * & \\
\hline Alcohol & -0.06 & 0.056 & -0.05 & -0.99 & & \\
\hline Caffeine (cups of caffeine beverages in a day) & -0.04 & 0.065 & -0.03 & -0.65 & & \\
\hline Smoking (yes $=1$, no=2) & 0.24 & 0.551 & 0.02 & 0.44 & & \\
\hline Step 3 & & & & & & $0.019 / .001$ \\
\hline Age & -0.02 & 0.023 & -0.05 & -1.04 & & \\
\hline Gender $($ male $=1$, female $=2)$ & -0.40 & 0.524 & -0.03 & -0.76 & & \\
\hline Marital status ( partner=1, no partner=2) & -0.17 & 0.352 & -0.02 & -0.49 & & \\
\hline Children $($ yes $=1$, no $=2)$ & -0.70 & 0.345 & -0.10 & -2.04 & * & \\
\hline Alcohol & -0.06 & 0.056 & -0.04 & -0.98 & & \\
\hline Caffeine (cups of caffeine beverages in a day) & -0.05 & 0.067 & -0.04 & -0.75 & & \\
\hline Smoking $($ yes $=1$, no $=2)$ & 0.23 & 0.553 & 0.02 & 0.42 & & \\
\hline Percentage position & 0.03 & 0.156 & 0.01 & 0.22 & & \\
\hline Number of years worked as a nurse & 0.01 & 0.041 & 0.02 & 0.36 & & \\
\hline Night shifts worked during the last year & 0.00 & 0.006 & 0.02 & 0.45 & & \\
\hline Step 4 & & & & & & $0.162 / .142^{\star * *}$ \\
\hline Age & -0.06 & 0.022 & -0.13 & -2.61 & ** & \\
\hline Gender $($ male $=1$, female $=2)$ & -0.67 & 0.492 & -0.05 & -1.36 & & \\
\hline Marital status (partner $=1$, no partner $=2$ ) & -0.06 & 0.329 & -0.01 & -0.19 & & \\
\hline Children $($ yes $=1$, no $=2)$ & -0.44 & 0.323 & -0.06 & -1.35 & & \\
\hline Alcohol & -0.06 & 0.052 & -0.04 & -1.05 & & \\
\hline Caffeine (cups of caffeine beverages in a day) & -0.02 & 0.062 & -0.01 & -0.31 & & \\
\hline Smoking $($ yes $=1, \mathrm{no}=2)$ & -0.29 & 0.522 & -0.02 & -0.56 & & \\
\hline Percentage position & 0.01 & 0.145 & 0.00 & 0.08 & & \\
\hline Number of years worked as a nurse & 0.04 & 0.038 & 0.05 & 1.01 & & \\
\hline Night shifts worked during the last year & 0.00 & 0.006 & 0.03 & 0.66 & & \\
\hline Morningness & 0.17 & 0.050 & 0.17 & 3.51 & $\star * *$ & \\
\hline Languidity & -0.22 & 0.046 & -0.23 & -4.78 & *** & \\
\hline Flexibility & -0.02 & 0.039 & -0.02 & -0.46 & & \\
\hline Hardiness & 0.12 & 0.032 & 0.15 & 3.63 & *** & \\
\hline
\end{tabular}

${ }^{*} p<0.05,{ }^{* *} p<0.01,{ }^{* * *} p<0.001$.

$\beta$, Standardised coefficients; B, non-standardised coefficients; SE B=the SE of $\beta$.

there were no significant findings regarding morningness, either in terms of evening or sleep-related night shift tolerance. This finding runs counter to previous reviews on this topic. ${ }^{29} 30$ Regarding evening shifts, which have been associated with problems in falling asleep following work, ${ }^{10}$ morning larks might have a shorter sleep onset latency than night owls, but they would be expected to have a shorter sleep duration due to earlier wake-up times. ${ }^{24}$ Thus, morningness may be associated with some advantages as well as some disadvantages when it comes to the evening shift, which might explain why we did not find any overall relationship between evening shift tolerance and morningness. We expected a negative relationship between sleep- related night shift tolerance and morningness as people with low scores on morningness seem to have better daytime sleep ${ }^{31}$ and are less sleepy during night shifts ${ }^{32}$ than people with higher scores on morningness. However, this was not supported by our findings. It might be that people with high scores on morningness can compensate for more disturbed daytime sleep as they seem to need less sleep than people with low scores on morningness. ${ }^{33}$ This fits well with findings showing that daytime sleep duration is significantly shorter than night-time sleep. ${ }^{10}$ Still, more research on the relationship between morningness and sleep-related shift work tolerance is needed, as there generally have been inconsistent findings related to this relationship. 
Table 3 Hierarchical regression analysis with sleep-related evening shift tolerance total score as the dependent variable $(\mathrm{N}=583)$

\begin{tabular}{|c|c|c|c|c|c|c|}
\hline Predictor & B & SE B & $\boldsymbol{\beta}$ & $\mathbf{t}$ & & $\mathrm{R}^{2} / \Delta \mathrm{R}^{2}$ \\
\hline Step 1 & & & & & & $0.030 / 0.030$ ** \\
\hline Age & -0.08 & 0.022 & -0.16 & -3.57 & $* * *$ & \\
\hline Gender $($ male $=1$, female $=2)$ & -0.59 & 0.581 & -0.04 & -1.01 & & \\
\hline Marital status (partner $=1$, no partner $=2$ ) & 0.83 & 0.398 & 0.09 & 2.10 & * & \\
\hline Children $($ yes $=1$, no=2) & -0.54 & 0.375 & -0.07 & -1.45 & & \\
\hline Step 2 & & & & & & $0.031 / 0.001$ \\
\hline Age & -0.07 & 0.024 & -0.15 & -3.07 & ** & \\
\hline Gender $($ male $=1$, female $=2)$ & -0.57 & 0.595 & -0.04 & -0.95 & & \\
\hline Marital status (partner $=1$, no partner $=2$ ) & 0.80 & 0.401 & 0.09 & 2.00 & * & \\
\hline Children (yes $=1, \mathrm{no}=2$ ) & -0.57 & 0.388 & -0.07 & -1.48 & & \\
\hline Alcohol & 0.04 & 0.064 & 0.02 & 0.55 & & \\
\hline Caffeine (cups of caffeine beverages in a day) & -0.03 & 0.075 & -0.02 & -0.36 & & \\
\hline Smoking (yes $=1, \mathrm{no}=2)$ & -0.27 & 0.632 & -0.02 & -0.43 & & \\
\hline Step 3 & & & & & & $0.032 / .001$ \\
\hline Age & -0.07 & 0.026 & -0.14 & -2.66 & ** & \\
\hline Gender $($ male $=1$, female $=2)$ & -0.53 & 0.601 & -0.04 & -0.89 & & \\
\hline Marital status (partner $=1$, no partner $=2$ ) & 0.78 & 0.403 & 0.09 & 1.94 & & \\
\hline Children (yes $=1, \mathrm{no}=2$ ) & -0.64 & 0.395 & -0.08 & -1.61 & & \\
\hline Alcohol & 0.03 & 0.064 & 0.02 & 0.50 & & \\
\hline Caffeine (cups of caffeine beverages in a day) & -0.03 & 0.076 & -0.02 & -0.35 & & \\
\hline Smoking (yes $=1$, no $=2)$ & -0.26 & 0.634 & -0.02 & -0.41 & & \\
\hline Percentage position & 0.13 & 0.179 & 0.03 & 0.70 & & \\
\hline Number of years worked as a nurse & -0.03 & 0.047 & -0.03 & -0.68 & & \\
\hline Night shifts worked during the last year & 0.00 & 0.007 & 0.01 & 0.23 & & \\
\hline Step 4 & & & & & & $0.122 / .090 * * *$ \\
\hline Age & -0.09 & 0.026 & -0.18 & -3.54 & $* \star *$ & \\
\hline Gender $($ male $=1$, female $=2)$ & -0.61 & 0.581 & -0.04 & -1.05 & & \\
\hline Marital status (partner $=1$, no partner $=2$ ) & 0.62 & 0.388 & 0.07 & 1.60 & & \\
\hline Children (yes $=1, \mathrm{no}=2)$ & -0.66 & 0.382 & -0.08 & -1.72 & & \\
\hline Alcohol & 0.02 & 0.062 & 0.02 & 0.36 & & \\
\hline Caffeine (cups of caffeine beverages in a day) & -0.05 & 0.073 & -0.03 & -0.68 & & \\
\hline Smoking (yes $=1, \mathrm{no}=2)$ & -0.25 & 0.616 & -0.02 & -0.40 & & \\
\hline Percentage position & 0.16 & 0.171 & 0.04 & 0.96 & & \\
\hline Number of years worked as a nurse & -0.00 & 0.045 & -0.00 & -0.05 & & \\
\hline Night shifts worked during the last year & -0.01 & 0.007 & -0.04 & -0.89 & & \\
\hline Morningness & -0.01 & 0.059 & -0.01 & -0.13 & & \\
\hline Languidity & -0.14 & 0.055 & -0.13 & -2.63 & ** & \\
\hline Flexibility & 0.20 & 0.046 & 0.20 & 4.41 & $\star * \star$ & \\
\hline Hardiness & 0.11 & 0.038 & 0.12 & 2.95 & ** & \\
\hline
\end{tabular}

${ }^{*} p<0.05,{ }^{* *} p<0.01,{ }^{* * *} p<0.001$.

$\beta$, Standardised coefficients; B, non-standardised coefficients; SE B, the SE of $\beta$.

Languidity was negatively associated with sleep-related shift work tolerance for the day, evening and night shifts, thus supporting the second hypothesis. High scores on languidity are associated with experiencing more difficulties in overcoming drowsiness, and participants with high scores on this trait tend to be more sensitive to sleep loss. ${ }^{17}$ ${ }^{19}$ Our findings concerning languidity are in line with previous studies on shift work. ${ }^{19} 27^{34-37}$ Thus, this appears to be a robust finding across studies.

Flexibility was positively associated with sleep-related shift tolerance for evening and night shifts, meaning that high scores on flexibility predict higher sleep-related shift work tolerance. A person who is flexible will be able to work and sleep at odd times compared to a person who is less flexible (rigid) in terms of sleep habits. ${ }^{19}$ Our findings are consistent with research indicating that high scores on flexibility are beneficial for shift work tolerance. ${ }^{19} 2735$ However, no association was found between flexibility and day shift tolerance, which suggests that flexibility is important when working at odd times, and this, in turn, is actually in line with the definition of flexibility. Thus, hypothesis 3 was only partly supported.

Hardiness was positively associated with sleep-related shift work tolerance for the day, evening and night shifts. Thus, hardiness predicted better adaptation to shift work across all shifts. The finding is in line with previous research suggesting that hardiness is a protective factor in terms of shift work tolerance in general, ${ }^{27} 37$ although one study failed to show this. ${ }^{34}$ 
Table 4 Hierarchical regression analysis with sleep-related night shift tolerance total score as the dependent variable $(\mathrm{N}=575)$

\begin{tabular}{|c|c|c|c|c|c|c|}
\hline Predictor & B & SE B & $\boldsymbol{\beta}$ & $\mathbf{t}$ & & $\mathrm{R}^{2} / \Delta \mathrm{R}^{2}$ \\
\hline Step 1 & & & & & & $0.024 / 0.024^{* *}$ \\
\hline Age & -0.06 & 0.027 & -0.10 & -2.22 & * & \\
\hline Gender $($ male $=1$, female $=2)$ & -0.37 & 0.700 & -0.02 & -0.54 & & \\
\hline Marital status (partner $=1$, no partner $=2$ ) & 1.00 & 0.479 & 0.09 & 2.10 & * & \\
\hline Children (yes $=1, \mathrm{no}=2$ ) & 0.14 & 0.452 & 0.02 & 0.32 & & \\
\hline Step 2 & & & & & & $0.029 / 0.006$ \\
\hline Age & -0.08 & 0.029 & -0.13 & -2.72 & ** & \\
\hline Gender $($ male $=1$, female $=2)$ & -0.32 & 0.714 & -0.02 & -0.45 & & \\
\hline Marital status (partner $=1$, no partner $=2$ ) & 1.01 & 0.482 & 0.09 & 2.09 & * & \\
\hline Children (yes $=1, \mathrm{no}=2$ ) & 0.20 & 0.466 & 0.02 & 0.43 & & \\
\hline Alcohol & -0.08 & 0.077 & -0.05 & -1.06 & & \\
\hline Caffeine (cups of caffeine beverages in a day) & 0.13 & 0.090 & 0.06 & 1.39 & & \\
\hline Smoking (yes $=1$, no $=2)$ & -0.40 & 0.759 & -0.02 & -0.52 & & \\
\hline Step 3 & & & & & & $0.034 / 0.005$ \\
\hline Age & -0.06 & 0.031 & -0.11 & -2.07 & * & \\
\hline Gender $($ male $=1$, female $=2)$ & -0.24 & 0.721 & -0.01 & -0.33 & & \\
\hline Marital status (partner $=1$, no partner $=2$ ) & 0.96 & 0.483 & 0.09 & 2.00 & * & \\
\hline Children (yes $=1, \mathrm{no}=2$ ) & 0.08 & 0.474 & 0.01 & 0.17 & & \\
\hline Alcohol & -0.09 & 0.077 & -0.05 & -1.19 & & \\
\hline Caffeine (cups of caffeine beverages in a day) & 0.12 & 0.092 & 0.06 & 1.32 & & \\
\hline Smoking $($ yes $=1, \mathrm{no}=2)$ & -0.35 & 0.761 & -0.02 & -0.46 & & \\
\hline Percentage position & 0.12 & 0.215 & 0.02 & 0.55 & & \\
\hline Number of years worked as a nurse & -0.08 & 0.056 & -0.06 & -1.34 & & \\
\hline Night shifts worked during the last year & 0.01 & 0.009 & 0.05 & 1.08 & & \\
\hline Step 4 & & & & & & $0.207 / .173^{\star \star *}$ \\
\hline Age & -0.08 & 0.029 & -0.14 & -2.84 & ** & \\
\hline Gender $($ male $=1$, female $=2)$ & -0.23 & 0.663 & -0.01 & -0.35 & & \\
\hline Marital status (partner $=1$, no partner $=2$ ) & 0.67 & 0.443 & 0.06 & 1.51 & & \\
\hline Children (yes $=1, \mathrm{no}=2)$ & -0.06 & 0.435 & -0.01 & -0.14 & & \\
\hline Alcohol & -0.11 & 0.071 & -0.06 & -1.34 & & \\
\hline Caffeine (cups of caffeine beverages in a day) & 0.06 & 0.084 & 0.03 & 0.74 & & \\
\hline Smoking (yes $=1, \mathrm{no}=2)$ & -0.11 & 0.703 & -0.01 & -0.58 & & \\
\hline Percentage position & 0.20 & 0.196 & 0.04 & 1.04 & & \\
\hline Number of years worked as a nurse & -0.03 & 0.051 & -0.03 & -0.58 & & \\
\hline Night shifts worked during the last year & -0.01 & 0.008 & -0.03 & -0.86 & & \\
\hline Morningness & -0.01 & 0.067 & -0.01 & -0.12 & & \\
\hline Languidity & -0.14 & 0.063 & -0.10 & -2.16 & * & \\
\hline Flexibility & 0.46 & 0.053 & 0.37 & 8.71 & $\star * \star$ & \\
\hline Hardiness & 0.09 & 0.043 & 0.09 & 2.15 & * & \\
\hline
\end{tabular}

${ }^{*} p<0.05,{ }^{* *} p<0.01,{ }^{* * *} p<0.001$.

$\beta$, Standardised coefficients; B, non-standardised coefficients; SE B, the SE of $\beta$.

Regarding the other variables included in the regression analyses, age was found to be negatively associated with sleep-related shift work tolerance across all three shifts. Young age predicted better shift work tolerance. This finding is in line with the majority of the studies in our previous review on this topic. ${ }^{17}$ This may be related to the speed of circadian adaptation, which seems to decline with age. ${ }^{38}$ However, our review also points to studies in which the opposite association has been found, as well as a few studies failing to find any association between age and shift work tolerance. ${ }^{17}$ The other demographic, work and lifestyle variables, was not associated with sleep-related shift work tolerance for any of the three shift types in the fourth and final step of the regression analyses.

\section{Strengths and limitations}

There are some limitations to the present study that need to be taken into account. First, the gender distribution was skewed with $91.5 \%$ of the sample being female respondents. Nevertheless, this reflects the true gender distribution in the population of nurses in Norway. Caution should be taken, however, when generalising the findings to male populations. A second potential problem with the present study concerns the 'healthy worker effect'. This effect refers to a selection process that leads to a workforce of shift workers who are healthier than day workers. ${ }^{39}$ Third, the present study included only four distinct personality traits. Other personality traits could, however, be highly relevant for shift work tolerance; thus, future studies should include a wider range 
of traits when investigating the relationship between shift work tolerance and personality. Furthermore, owing to missing data, the sample sizes for some of the variables were somewhat small. As the present study assessed shift work tolerance specifically for different shifts, comparisons with other studies cannot be conducted without some reservations. However, our findings are by and large in line with previous studies regarding shift work tolerance. Cronbach's $\alpha$ for the AUDIT-C and DS measures were quite low, but it should be noted at the same time that both scales contain a low number of items. Even though there was no difference between those who participated and those who did not participate in wave 3 on any of the four personality traits (results not shown), the personality traits may still have had an influence on participation in the study in the first place. Thus, we cannot rule out that selection factors may have influenced the relationships between shift work tolerance and personality in the present study.

Despite its limitations, there are also several strengths in the present study. First, we used a prospective study design, where personality variables were assessed 2 years prior to assessment of sleep-related shift work tolerance. The use of this type of study design reduces the influence of confounding variable problems (such as a stressful period) that could affect the personality traits as well as insomnia at a certain point in time. Second, this is the very first study to investigate whether personality variables predict sleep-related shift work tolerance separately for different shifts. Moreover, in order to assess sleep-related shift work tolerance, we used a new and validated instrument, BSWSQ which has been found to meet the necessary psychometric standards. ${ }^{21}$ Also, BSWSQ was specifically constructed in order to assess sleep-related shift work tolerance/intolerance and the items reflect insomnia and sleepiness/tiredness related to specific shifts. Still, other sleep-related variables, such as insufficient sleep, may better reflect sleep-related shift work tolerance. ${ }^{40}$ It could thus be beneficial for future research to assess sleep-related shift work tolerance/intolerance in relation to other sleep-related variables. The other instruments applied in the present study were standardised and well-validated. Furthermore, we controlled for several relevant variables in the analysis (age, percentage of fulltime equivalent, number of nights worked last year, marital status, children living at home, years of shift work experience, as well as consumption of alcohol, caffeine and smoking). Despite the response rate in wave 1 being quite low, more than $75 \%$ of those who participated in wave 1 also participated in wave 3 . In addition, the present study was based on a large and homogeneous sample $(\mathrm{n}=700)$, which reduces the influence of possible confounding variables. However, this may complicate the generalisation to other occupations.

\section{Implications and suggestions for further research}

The research field would benefit from an enhanced consensus on how to define shift work as a concept.
Moreover, future studies should continue to measure sleep-related shift work tolerance specifically associated with different shifts, as this knowledge may have practical implications for recruitment and personnel selection. On the basis of knowledge obtained in the present and previous studies, employers may run personality tests in terms of personality variables such as morningness, flexibility, languidity and hardiness in order to get some indication of how well the employee will deal with different types of shift work. Further, based on the scorings obtained, it may be easier to adjust the shift work to the employees. This may in turn cause less complications related to sleep and less negative health consequences. It should, however, be noted that the relationship between personality and shift work tolerance is not very strong and some previous research has found equivocal results. It would also be beneficial to employ longitudinal designs and to assess shift work tolerance in terms of concepts other than sleep (eg, gastrointestinal symptoms, mood, etc) with subjective and objective measures (eg, metabolic and immunological parameters).

In conclusion, the present study supports the notion that personality variables over time can predict sleep-related shift work tolerance. The findings indicate that hardiness and languidity predict sleep-related shift work tolerance across all shift types, while the effects of flexibility and morningness appear to depend on the specific shift.

\section{Author affiliations}

${ }^{1}$ Department of Psychosocial Science, University of Bergen, Bergen, Norway ${ }^{2}$ Department of Global Public Health and Primary Care, University of Bergen, Bergen, Norway

${ }^{3}$ Norwegian Competence Disorder for Sleep Disorders, Haukeland University Hospital, Bergen, Norway

Contributors SS, IF and SP drafted the manuscript and conducted the data analyses. BB, BM and SP designed the SUSSH study and were responsible for data collection and also made revisions to the manuscript. EF made substantial revisions of the manuscript and provided comments. All authors have read and approved the final manuscript.

Funding The Western Norway Regional Health Authorities and the Norwegian Nurses Organisation.

Competing interests None.

Patient consent Obtained.

Ethics approval The Regional Committee for Medical Research Ethics, the Norwegian Data Inspectorate and the Norwegian Health Directorate.

Provenance and peer review Not commissioned; externally peer reviewed.

Data sharing statement The original data of this study can be accessed by emailing staale.pallesen@psysp.uib.no

Open Access This is an Open Access article distributed in accordance with the Creative Commons Attribution Non Commercial (CC BY-NC 3.0) license, which permits others to distribute, remix, adapt, build upon this work noncommercially, and license their derivative works on different terms, provided the original work is properly cited and the use is non-commercial. See: http:// creativecommons.org/licenses/by-nc/3.0/

\section{REFERENCES}

1. Monk TH, Folkard S. Making shift work tolerable. London: Taylor \& Francis, 1992 
2. Åkerstedt T. Shift work and disturbed sleep/wakefulness. Sleep Med Rev 1998;2:117-28.

3. Statistics Norway. Arbeidstidsordninger, arbeidskraftundersøkelsen, 2012. 2013. Retrieved 10 June 2013. http://www.ssb.no/akutidord

4. Bøggild $H$, Knutsson A. Shift work, risk factors and cardiovascular disease. Scand J Work Environ Health 1999;25:85-99.

5. Knutsson A, Bøggild $\mathrm{H}$. Gastrointestinal disorder among shift workers. Scand J Work Environ Health 2010;36:85-95.

6. Megdal SP, Kroenke CH, Laden F, et al. Night work and breast cancer risk: a systematic review and meta-analysis. Eur J Cancer 2005;41:2023-32.

7. Karlsson B, Knutsson A, Lindahl B. Is there an association between shift work and having a metabolic syndrome? Results from a population based study of 27485 people. Occup Environ Med 2001;58:747-52.

8. Bara AC, Arber $\mathrm{S}$. Working shifts and mental health-findings from the British Household Panel Survey (1995-2005). Scand J Work Environ Health 2009;35:361-7.

9. Presser HB. Nonstandard work schedules and marital instability. J Marriage Fam 2000;62:93-110.

10. Åkerstedt T. Shift work and disturbed sleep/wakefulness. Occup Med (Lond) 2003;53:89-94.

11. Folkard S, Tucker P. Shift work, safety and productivity. Occup Med (Lond) 2003;53:95-101.

12. Smith L, Folkard S, Poole CJM. Increased injuries on night shift. Lancet 1994;344:1137-9.

13. Åkerstedt T. Work hours, sleepiness and the underlying mechanisms. J Sleep Res 1995;4:15-22.

14. Folkard S, Monk TH, Lobuan MC. Towards a predictive test of adjustment to shift work. Ergonomics 1979;22:79-91.

15. Andlauer $\mathrm{P}$, Reinberg $\mathrm{A}$, Fourré $\mathrm{L}$, et al. Amplitude of the oral temperature circadian rhythm and the tolerance to shift-work. J Physiol (Paris) 1979;75:507.

16. Costa G. Multidimensional aspects related to shiftworkers' health and well-being. Rev Saude Publ 2004;38:86-91.

17. Saksvik IB, Bjorvatn $\mathrm{B}$, Hetland $\mathrm{H}$, et al. Individual differences in tolerance to shift work-a systematic review. Sleep Med Rev 2011;15:221-35.

18. Roberts RD, Kyllonen PC. Morningness-eveningness and intelligence: early to bed, early to rise will likely make you anything but wise! Pers Individ Dif 1999;27:1123-33.

19. Di Milia L, Smith PA, Folkard S. A validation of the revised circadian type inventory in a working sample. Pers Individ Dif 2005;39:1293-305

20. Kobasa SC. Stressful life events, personality, and health: an inquiry into hardiness. J Pers Soc Psychol 1979;37:1-11.

21. Flo $E$, Bjorvatn $B$, Folkard $S$, et al. A reliability and validity study of the Bergen Shift Work Sleep Questionnaire in nurses working three-shift rotations. Chronobiol Int 2012;29:937-46.

22. Bush K, Kivlahan DR, McDonell MB, et al. The AUDIT Alcohol Consumption Questions (AUDIT-C): an effective brief screening test for problem drinking. Arch Intern Med 1998;158:1789-95.
23. Torsvall L, Åkerstedt T. A diurnal type scale: construction, consistency and validation in shift work. Scand J Work Environ Health 1980:283-90.

24. Thun E, Bjorvatn B, Osland T, et al. An actigraphic validation study of seven morningness-eveningness inventories. Eur Psychol 2012;17:222-30.

25. Bartone PT. Predictors of stress-related illness in city bus drivers. J Occup Environ Med 1989;31:657-63.

26. Hystad SW, Eid J, Johnsen BH, et al. Psychometric properties of the revised Norwegian dispositional resilience (hardiness) scale. Scand J Psychol 2010;51:237-45.

27. Saksvik-Lehouillier I, Bjorvatn B, Hetland $\mathrm{H}$, et al. Individual, situational and lifestyle factors related to shift work tolerance among nurses who are new to and experienced in night work. J Adv Nurs 2012;69:1136-46.

28. Soehner AM, Kennedy KS, Monk TH. Circadian preference and sleep-wake regularity: associations with self-report sleep parameters in daytime-working adults. Chronobiol Int 2011;28:802-9.

29. Cavallera G, Giudici S. Morningness and eveningness personality: a survey in literature from 1995 up till 2006. Pers Individ Dif 2008;44:3-21.

30. Kantermann T, Juda M, Vetter C, et al. Shift-work research: where do we stand, where should we go? Sleep Biol Rhythms 2010;8:95-105.

31. Khaleque A. Sleep deficiency and quality of life of shift workers. Soc Indic Res 1999;46:181-9.

32. Kageyama T, Kobayashi T, Abe-Gotoh A. Correlates to sleepiness on night shift among male workers engaged in three-shift work in a chemical plant: its association with sleep practice and job stress. Ind Health 2011;49:634-41.

33. Taillard J, Philip P, Bioulac B. Morningness/eveningness and the need for sleep. J Sleep Res 1999;8:291-5.

34. Flo E, Pallesen S, Magerøy N, et al. Shift work disorder in nursesassessment, prevalence and related health problems. PLOS ONE 2012;7:e33981.

35. Ognianova V, Dalbokova D, Stanchev V. Stress states, alertness and individual differences under 12-hour shiftwork. Int J Ind Ergonom 1998;21:283-91.

36. Smith CS, Robie C, Folkard S, et al. A process model of shiftwork and health. J Occup Health Psychol 1999;4:207-18.

37. Natvik S, Bjorvatn B, Moen BE, et al. Personality factors related to shift work tolerance in two-and three-shift workers. Appl Ergon 2011;42:719-24.

38. Härmä MI, Hakola T, Akerstedt T, et al. Age and adjustment to night work. Occup Environ Med 1994;51:568-73.

39. Knutsson A. Methodological aspects of shift-work research Chronobiol Int 2004;21:1037-47.

40. Axelsson J, Åkerstedt T, Kecklund G, et al. Tolerance to shift workhow does it relate to sleep and wakefulness? Int Arch Occup Environ Health 2004;77:121-9. 